\title{
A Novel NHERF1 Mutation in Human Breast Cancer and Effects on Malignant Progression
}

\author{
XIAOMEI YANG ${ }^{1-4}$, GUIFANG DU ${ }^{1-4}$, ZHEN YU $^{1-4}$, YANG SI ${ }^{1-4}$, TRACEY A. MARTIN ${ }^{5}$, \\ JUNQI HE ${ }^{1-4}$, SHAN CHENG ${ }^{1-4}$ and WEN G. JIANG ${ }^{2-5}$ \\ ${ }^{1}$ Department of Biochemistry and Molecular Biology, Basic Medical School, \\ ${ }^{2}$ Cancer Institute of Capital Medical University, ${ }^{3}$ Beijing Key Laboratory for Cancer \\ Invasion and Metastasis Research, and ${ }^{4}$ Beijing International Cooperation Base for Science \\ and Technology on China-UK Cancer Research, Capital Medical University, Beijing, P.R. China; \\ ${ }^{5}$ Cardiff China Medical Research Collaborative, Cardiff University School of Medicine, Heath Park, Cardiff, U.K.
}

\begin{abstract}
Na}^{+} / \mathrm{H}^{+}$exchanger regulatory factor 1 (NHERF1) has been reported to interact with post-synaptic density protein/Drosophila disc large tumour suppressor/zonula occludens 1 protein (PDZ) binding proteins by its two PDZ domains. These associations have effects on cellular signal transductions. NHERF1 has also been indicated as a cancerrelated gene in several solid tumour types. We identified a novel mutation (A190D), of the PDZ2 domain of NHERF1 in breast cancer tissues. NHERF1 A190D mutation abolished NHERF1 modulation of proliferation and migration. In this study, we found that NHERF1 A190D mutation increased nuclear localisation of the protein compared to wild-type NHERF1. It has been reported that YES-associated protein (YAP) interacts with NHERF1. Here we found that NHERF1 A190D mutation increased the binding affinity between NHERF1 and YAP, which inhibited the phosphorylation of YAP. These data suggest that wild-type NHERF1 acts as a tumour suppressor, while NHERF1 A190D mutation abolishes the tumour-suppressive effect in cancer cells, due to A190D mutation-mediated nuclear NHERF1 translocation and induction of YAP phosphorylation.
\end{abstract}

This article is freely accessible online.

Correspondence to: Wen G. Jiang, Metastasis \& Angiogenesis Research Group, Cardiff China Medical Research Collaborative, Cardiff University School of Medicine, Heath Park, Cardiff CF14 4XN, UK. E-mail: JiangW@ cardiff.ac.uk; Shan Cheng, Department of Biochemistry and Molecular Biology, Capital Medical University, Beijing 100069, China. Tel: +86 1083950184, e-mail: chengs@ccmu.edu.cn; Junqi He, Department of Biochemistry and Molecular Biology, Basic Medical School, Capital Medical University, Beijing 100069, China. Tel: +86 1083950125, e-mail: jq_he@ccmu.edu.cn

Key Words: NHERF1 mutation, progression, breast cancer.
$\mathrm{Na}^{+} / \mathrm{H}^{+}$exchanger regulatory factor 1 (NHERF1) is a typical scaffold protein of the post-synaptic density protein/ Drosophila disc large tumour suppressor/zonula occludens 1 protein (PDZ) domain-containing protein family. NHERF1 has two PDZ domains, PDZ1 and PDZ2, followed by an ezrin-radixinmoesin binding region (1). The PDZ1 domain (11-97 amino acids) of NHERF1 binds to proteins containing the PDZ binding motif such as epidermal growth factor receptor (EGFR), platelet-derived growth factor receptor (PDGFR), phosphatase and tensin homolog deleted on chromosome 10 (PTEN), beta 2-adrenergic receptors, cystic fibrosis transmembrane conductance regulator and spleen tyrosine kinase (SYK) (2-7), while the PDZ2 domain (150-237 amino acids) of NHERF1 binds to other proteins such as yes-associated protein 65 (YAP65), sodium hydrogen exchanger 3, phospholipase C $\beta 3$ and $\beta$-catenin (8-13). These protein interactions lead to changes in subcellular location of the proteins and cellular functions by different signal pathways $(14,15)$.

Genetic alterations of cancer-related genes, such as $p 53$, PTEN, breast cancer 1 (BRCAI) and BRCA2, have been reported to affect carcinogenesis and progression (16-19). NHERF 1 has been shown to be a potential cancer-related gene and suppressor of tumour growth (20-22). Genetic mutations of NHERF 1 have also been reported in some cancer tissues and cancer cell lines. Several missense mutations have been found in the two PDZ domains of NHERF1 which have impacts on cellular functions. For example, NHERF1 E43G mutation has been found to inhibit EGFR signaling (23). NHERF1 E68A mutation has been found to abolish the association with type $2 \mathrm{a}$ sodium-phosphate co-transporter to affect cyclic AMP (cAMP) production and protein kinase $\mathrm{C}$ activity (15). Missense mutation NHERF1 R153Q, K172N and R180W in exon 2 have been found in primary breast tumours and MDA-MB-231 cell lines and are related to protein stability or alter the interaction between NHERF1 and SYK/PTEN/PDGFR (7, 24, 25). Missense mutation NHERF1 E225K in exon 3 expressed in 
cultured renal cells which also related to protein stability, the generation of cAMP and phosphate transportation (26).

In the present study, we identified a novel mutation of NHERF1, A190D, and explored its effects on cellular functions and interactions with signal molecules. The results indicate that this new NHERF1 mutation has important implication on the biological functions of cancer cells, in carcinogenesis and progression.

\section{Materials and Methods}

Cell lines and culture. Human breast cancer cell line MCF-7 and nonsmall cell lung cancer cell line SK-MES-1 were obtained from the European Collection for Animal Cell Cultures (Salisbury, Wiltshire, UK). MCF-7-riNHERF1 cell lines were constructed by stable transfection of MCF-7 cells with ribozyme targeted to NHERF1 thereby knocking down expression of NHREF1 (25). HEK-293 and COS-7 cells were obtained from the American Type Culture Collection (Manassas, VA, USA). All cells were maintained in Dulbecco's modified Eagle's medium (DMEM) containing $10 \%$ foetal bovine serum, $100 \mathrm{U} / \mathrm{ml}$ penicillin and $100 \mu \mathrm{g} / \mathrm{ml}$ streptomycin (Gibco BRC, Paisley, UK) at $37^{\circ} \mathrm{C}$, with $5 \% \mathrm{CO}_{2}$.

Human mammary specimens. Tissue samples were obtained from a total of 20 Chinese patients who had breast cancer. The tissues were collected immediately after mastectomy and snap-frozen in liquid nitrogen. The study received local Ethics Research Committee (approval number 2013SY15). None of the patients had any underlying medical condition and none was taking any medication. The genomic DNA from 20 frozen Chinese breast cancer tissues was extracted using the DNeasy kit (Qiagen, Hilden, Germany). All six exons of NHERF1 were amplified by PCR as described before (23). The amplified sequences were analysed by single-strand conformation polymorphism also as previously described (27).

Plasmids and cell transfection. The cDNA of wild-type NHERF1 (NHERF-WT) and NHERF1 A190D mutation were obtained by polymerase chain reaction (PCR) and cloned into $\mathrm{pEASY}^{\mathrm{TM}} \mathrm{-M} 2$ vector using pEASY-Blunt M2 Expression Kit (TransGen, Beijing, China) according to the manufacturer's instructions. Green fluorescent protein (GFP)-NHERF-WT and GFP-NHERF-A190D constructs were verified by DNA sequencing. Glutathione-S-transferase (GST)-NHERF1 construct was kindly provided by Dr. Jiale Dai (MD Anderson Cancer Center, Houston, TX, USA). GST-NHERF-A190D mutation construct was generated from the wild type using Fast MultiSite Mutagenesis System kit (TransGen) and verified by DNA sequencing.

Cell transfections were performed using Lipofectamine reagent (Invitrogen, Carlsbad, CA, USA) by following the manufacturer's instructions. The stably transfected cell lines were selected in selected culture medium containing $600 \mu \mathrm{g} / \mathrm{ml} \mathrm{G} 418$. The expression of NHERF1 was verified by western blotting.

Cell proliferation assay. MCF-7-riNHERF1 and SK-MES-1 cells were seeded into 96-well plates in sextuplicate at a density of 2,000 cells per well. Plates were then incubated for 24, 48, 72 and $96 \mathrm{~h}$ before added CCK- 8 reagent (Dojindo, Kumamoto, Japan), by following the manufacturer's instructions. The absorbance was measured at $450 \mathrm{~nm}$ using EnSpire label microplate reader (PerkinElmer, Waltham, MA, USA).
Wound-healing assay. MCF-7-riNHERF1 and SK-MES-1 cells were seeded into 6 -well plates at a density of $5 \times 10^{5}$ cells per well and cultured until confluent. The layer of cells was scraped with a 5gauge needle to create a wound. Images of the wound were recorded under microscopy at different time points $(0,6,12$ and $24 \mathrm{~h})$. The width of wounds was evaluated by Image-Pro plus (National Institutes of Health, Bethesda, MD, USA).

Immunofluorescence staining. HEK-293 cells were seeded on a cover glass in 6-well plates and cultured overnight. The adherent cells were fixed with $4 \%$ paraformaldehyde and stained with 5 $\mu \mathrm{g} / \mathrm{ml}$ Hochest 33258 (Zhongshan, China). Images were acquired under confocal microscopy (LAS AF-TCS SP5; Leica Microsystems Inc., Exton, PA, USA).

Nuclear and cytoplasmic protein extraction. The nuclear and cytoplasmic protein extracts were prepared using the Nucl-CytoMem Preparation kit (Applygen Technologies, China) according to the manufacturer's instructions. Briefly, the HEK-293 cells were digested and washed with cold phosphate-buffered saline. Then the cell pellets from centrifugation were incubated with cytoplasmic extraction and nuclear extraction reagent. The extractis were analysed by western blotting.

GST pull-down assays and western blotting. GST pull-down assays and western blotting were performed as described previously (28). Antibody to NHERF1 was purchased from Becton Dickinson Company (Franklin Lake, NJ, USA), Glyceraldehyde-3-phosphate dehydrogenase (GAPDH) was used as an internal control (Santa Cruz Biotechnology, Santa Cruz, CA, USA). GFP was purchased from MBL life science (Nagoya, Japan). Histone deacetylase protein (HDAC) (Santa Cruz Biotechnology) was used as nuclear protein control, and $\alpha$-tubulin was used as cytoplasmic protein control (Santa Cruz Biotechnology). YAP was purchased from Santa Cruz Biotechnology (Santa Cruz Biotechnology) and phospho-YAP (Ser127) was purchased from Cell Signalling Technology (Beverly, MA, USA). Horseradish peroxidase-conjugated secondary antibodies were obtained from ZSGB-BIO (Beijing, China).

Statistical analysis. Statistical analysis was performed using SPSS (IBM Corp, Armonk, New York, US). p-Value of less than 0.05 was considered to be statistically significant.

\section{Results}

NHERF1 A190D mutation identified in breast cancer. A novel point-mutation, cytosine mutated to adenine at nucleotide position 569, was confirmed by DNA sequencing (Figure 1A). This point-mutation resulted in substitution in codon 190 (Ala/A-Asp/D), and is named here as A190D. The alanine 190 has been highly conserved in the PDZ2 domain of NHERF1 protein throughout evolution with other species as shown by the alignment of the NHERF1 protein sequence (Figure 1B). This suggests that the novel A190D mutation, not found in the 1000 Genomes Project database (http://browser.1000genomes.org/index.html), has the potential to affected the scaffold functions of the NHERF1 protein. 
A

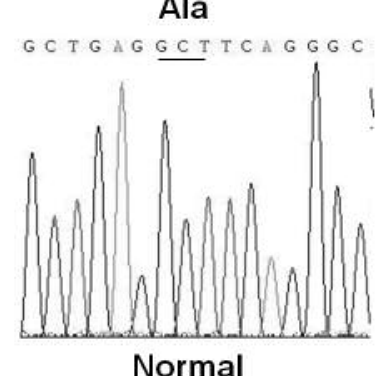

Asp

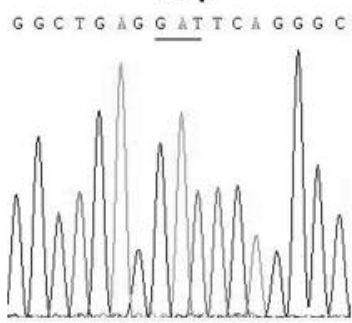

Breast Cancer

\begin{tabular}{|c|c|c|}
\hline $\begin{array}{l}\text { UniProt } \\
\text { Accession } \\
\text { Number }\end{array}$ & Amino acid sequence & Species \\
\hline 014745 & FNLHSDKSKPGQFIRSVDPDSPAEASGLRAQDRIVEVNGVCMEGK & HUMAN \\
\hline P70441 & FNLHSDKSKPGQFIRAVDPDSPAEASGLRAQDRIVEVNGVCMEGK & MOUSE \\
\hline Q9JJ19 & FNLHSDKSKPGQFIRAVDPDSPAEASGLRAQDRIVEVNGVCMEGK & RAT \\
\hline Q4R6G4 & FNLHSDKSKPGQFIRSVDPDSPAEASGLRAQDRIVEVNGVCMEGK & MACAQUE \\
\hline Q3SZK8 & FNLHSDKSKPGQFIRAVDPDSPAEASGLRAQDRIVEVNGVCVEGK & BOVIN \\
\hline Q28619 & FNLHSDKSRPGQFIRAVDPDSPAEASGLREQDRIVEVNGVCVEGK & RABBIT \\
\hline
\end{tabular}

Figure 1. A: Novel mutation of $\mathrm{Na}^{+} / \mathrm{H}^{+}$exchanger regulatory factor (NHERF1) (A190D) identified in patients with breast cancer. A: The NHERF1 gene mutation (GCT to GAT) was identified by sequencing, which would cause a switch of codon 190 (Ala/A-Asp/D). B: The mutation site corresponded to a conserved basic residue in the post-synaptic density protein/Drosophila disc large tumour suppressor/zonula occludens 1 protein (PDZ)2 domain of NHERF1 protein.

NHERF1 A190D mutation abolished the NHERF1 inhibition of cellular proliferation and migration. SK-MES-1 and MCF7-riNHERF1 breast cancer cells were used in proliferation and migration assays because NHERF1 was poorly expressed in SK-MES-1 cells (23). Our previous studies showed NHERF1 as a tumour-suppressor gene in breast cancer cells (25). SKMES-1 cells were stably transfected with NHERF1 WT or A190D mutation plasmid and expressions was detected by western blotting (Figure 2A). The expression of WT and mutated NHERF1 protein in the respectively transfected cells was considerably increased compared to parental and vector control cells. The impact of NHERF1 A190D mutation on cellular proliferation and migration were subsequently tested with these cells. The rate of cell proliferation induced by NHERF1 A190D mutation increased by $35 \%$ (day 3) compared to WT NHERF1 (Figure 2B). Cellular migration in the wound-healing assay by cells carrying NHERF1 A190D mutation increased by $121 \%(12 \mathrm{~h})$ compared to cells with WT NHERF1 (Figure 2C).

MCF-7 cells expressed high levels of NHERF1. Using riNHERF1 plasmids, we established a stable NHERF 1 knockdown cell line, MCF-7-riNHERF1, following transfection and selection. NHERF1-WT or NHERF1 A190D mutation plasmids were then stably transfected into the MCF7-riNHERF1 cells, which resulted in expression of both WT and mutated NHERF1 proteins, respectively, as detected by western blotting (Figure 2A). Using these new MCF7 sublines, it was found that cellular proliferation and migration increased $59 \%$ (day 3) and 120\% (12 h), respectively induced by NHERF1 A190D mutation compared to WT NHERF1 (Figure 2B and C). These results indicate that NHERF1 A190D mutation abrogated the inhibition of proliferation and migration by NHERF1 in SK-MES-1 and MCF-7-riNHERF1 cells.

Subcellular localization of mutated NHERF1 protein. As reported before (29), mutation of NHERF1 affects subcellular localization of its protein. We therefore also explored the effect of NHERF1 A190D mutation on localization by confocal assay. NHERF1-WT and NHERF-A190D were transfected into HEK-293 cells separately and detected by confocal microscopy. The fluorescence intensity in the nucleus increased, indicating a rise in nucleus localization of mutated NHERF1 protein, in clear contrast to the WT NHERF1 protein (Figure 3A). To further confirm this finding, the cytoplasmic and nuclear fractions were extracted from the respective cells and the levels of proteins in these fractions were further analysed by western blotting. Mutated NHERF1 protein was increased in the nucleus but decreased in the cytoplasm compared with WT NHERF1 protein using HDAC and $\alpha$ tubulin as nuclear and cytoplasmic protein controls, respectively, in clear contrast to cells transfected with NHERF1-WT (Figure 3B and C). These data indicate 
A

SK-MES-1

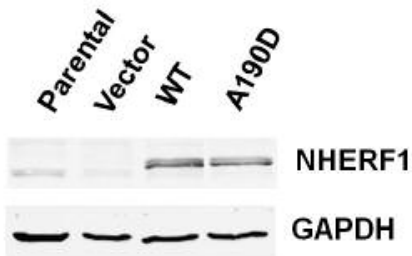

B

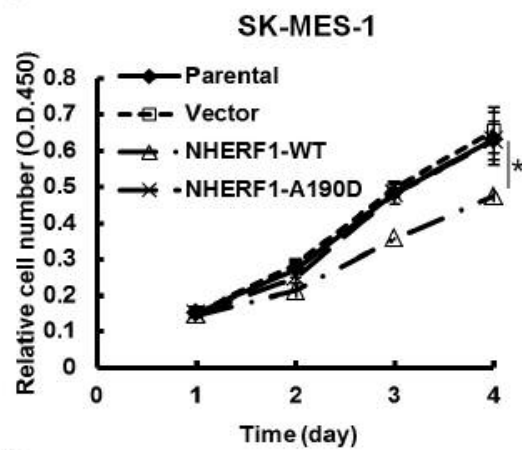

C

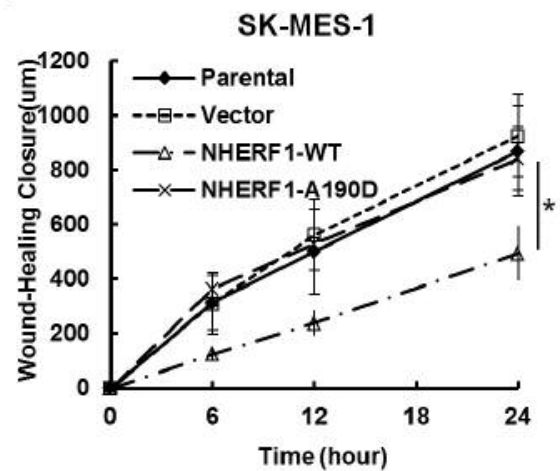

MCF-7-riNHERF1

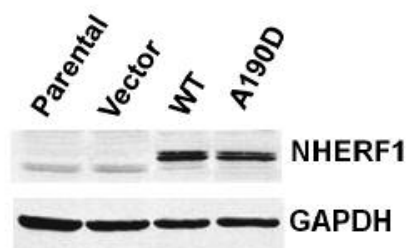

MCF-7-riNHERF1

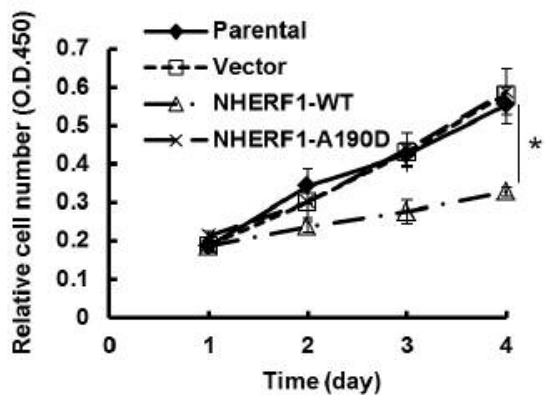

MCF-7-riNHERF1

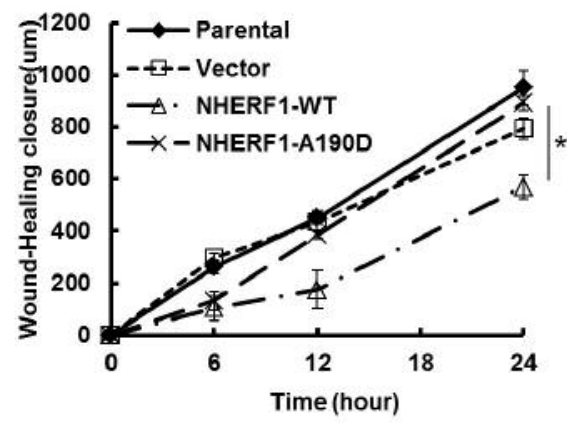

Figure 2. A: $\mathrm{Na}^{+} / \mathrm{H}^{+}$exchanger regulatory factor (NHERF1)-wild type (WT) and the NHERF1-A190D plasmids were stably transfected into SKMES-1 cells and MCF-7 cells in which NHERF1 was stably knocked-down by riNHERF1 (MCF-7-riNHERF1). NHREF1 protein expression was then detected by western blotting. Glyceraldehyde-3-phosphate dehydrogenase (GAPDH) was used as loading controls. NHERF1 A190D mutation abolished the inhibition of proliferation $(B)$ and migration $(C)$ induced by WT NHERF1 in SK-MES-1 cells and MCF-7-riNHERF1 cells. The results represent mean values $\pm S D$ of three independent experiments. ${ }^{*} p<0.05$.

NHERF1 A190D mutation results in increased translocation of NHERF1 protein to the nucleus compared to WT NHREF1.

NHERF1 A190D mutation enhances NHERF1 association with YAP. It has been reported NHERF1 associates with YAP through its PDZ2 domain (8). To determine the impact of NHERF1 A190D mutation on the interaction between NHERF1 and YAP, GST pull down assay was carried out. GST-NHERF1-WT and GST-NHERF1-A190D fusion proteins were purified and incubated with lysates of COS-7 cell expressing full-length YAP. It was very interesting to note that the level of YAP associated with mutated NHERF1 fusion protein increased by $59 \%$ compared with WT NHERF1 (Figure 4A and B). The results indicate that YAP preferentially associated with mutated NHERF1 protein.

NHERF1 A190D mutation affects phosphorylation of YAP. Phosphorylation of YAP is essential for its translocation into the nucleus in order for it to act as transcriptional coactivator. Therefore, we investigated the effect of mutated NHERF1 on interaction and phosphorylation of YAP. Overexpression of NHERF1 facilitated the phosphorylation of YAP. Phosphorylation of YAP was seen in both both NHERF1-A190D and NHERF1-WT transfected cells. 
A
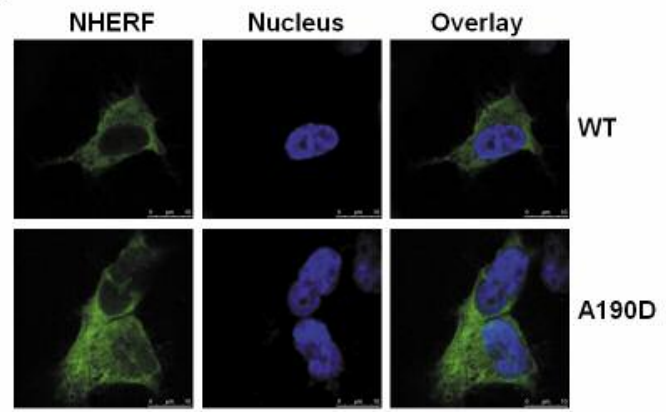

B

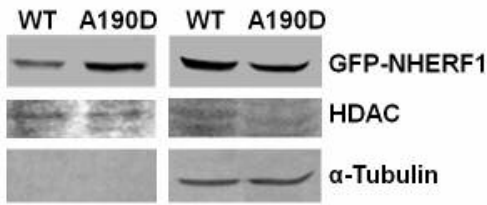

C

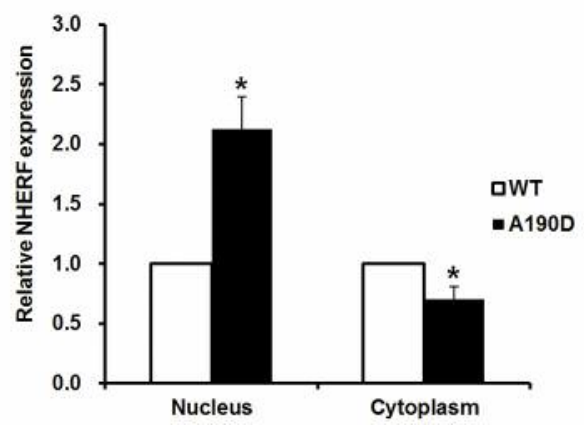

Figure 3. A: $\mathrm{Na}^{+} / \mathrm{H}^{+}$exchanger regulatory factor 1 (NHERF1) A190D mutation increased the localization of NHERF1 protein in the nucleus of HEK-293 cells compared to wild-type (WT) NHERF1, as analyzed by confocal microscopy. B: Expression of NHERF1 A190D mutation increased in nucleus and decreased in the cytoplasm of HEK-293 cells compared with WT NHERF1 as shown by western blotting. C: Quantification of the expression of NHERF1 shown in (B). Histone deacetylase protein (HDAC) and $\alpha$-tubulin were used as nucleus and cytoplasm loading controls. The results represent mean values $\pm S D$ of three independent experiments. ${ }^{*} p<0.05$.

However, the phosphorylation of YAP in cells carrying NHERF 1 A190D was significantly lower than that in cells with WT NHERF1 (Figure 5).

\section{Discussion}

The NHERF 1 gene has been reported as a cancer-related gene in breast cancer. Up-regulation of NHERF1 in tumours has been associated with carcinogenesis, progression, and poor prognosis, indicating that NHERF1 is a potential oncoprotein in breast cancer and colon cancer $(30,31)$. However in

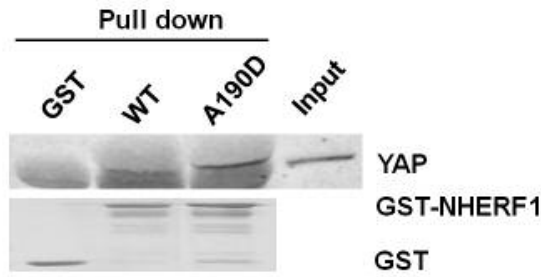

B

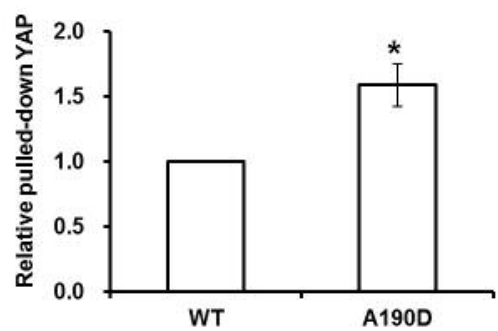

Figure 4. $\mathrm{Na}^{+} / \mathrm{H}^{+}$exchanger regulatory factor (NHERF1) A190D mutation enhanced the association between NHERF1 and YESassociated protein (YAP). A: Glutathione-S-transferase (GST) fusion with NHERF1 WT or A190D proteins were purified and incubated with COS-7 cells. The pulled-down precipitation was assayed by western blotting. B: Quantification of YAP pulled down by GST-NHERF-WT and GST-NHERF-A190D fusion proteins. The results represent mean values $\pm S D$ of three independent experiments. ${ }^{*} p<0.05$.

A

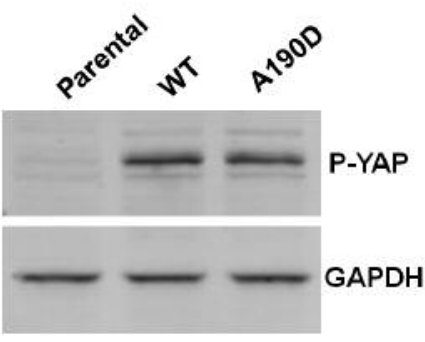

B

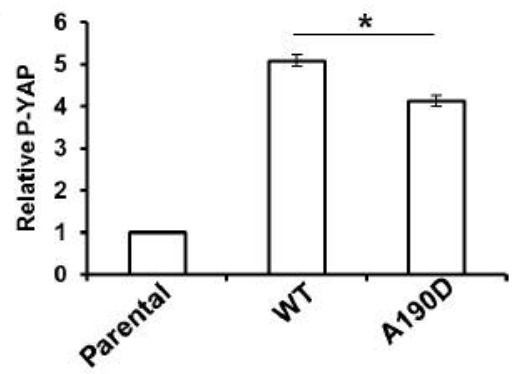

Figure 5. $\mathrm{Na}^{+} / \mathrm{H}^{+}$exchanger regulatory factor (NHERF1) A190D mutation increased phosphorylation of YES-associated protein $(Y A P)$ in MCF-7 cells in which NHERF1 was stably knocked-down by riNHERF1 (MCF-7-riNHERF1). A: NHERF1-WT or -A190D mutation fusion plasmid was transfected separately into MCF-7-riNHERF1 cells. YAP and phosphorylated YAP (P-YAP) were detected by western blotting. $B$ : Quantification of P-YAP shown in (A). The results represent mean values $\pm S D$ of three independent experiments. ${ }^{*} p<0.05$. 
contrast, NHERF1 has been to shown to act as anticancer gene in invasive breast carcinomas and breast cancer cells $(21,32)$. These contrasting results may suggest that NHERF1 has diverse roles in breast cancer, possibly via different patterns of expression or mutations in different subtypes.

In our previous study, we found NHERF1 to act as an anticancer gene related to malignant phenotypes (25). There have been several reports of missense mutations in NHERF1 PDZ domains in human breast cancer $(7,23,25,29)$. In the present study, the coding region and the intron-exon junctions of NHERF 1 were analysed in 20 human breast cancer tissues. A novel NHERF1 sequence variant (GCT to GAT), resulted in an amino acid change at residue 190 from alanine to aspartic acid, in the PDZ2 domain of NHERF1. We found overexpression of mutated NHERF1 abolished the suppression of proliferation and migration induced with WT NHERF1 in NHERF1 knock-down cells. This suggests WT NHERF 1 has a tumour-suppressive role, while NHERF 1 A190D mutation abolishes this tumour suppressive function of NHERF1 protein.

NHERF1 A190D mutation changed nonpolar alanine to acidic polar aspartic acid. This might lead to spatial structural changes of NHERF1 protein, resulting in alteration of subcellular location and biological activities in cancer cells.

NHERF1 is a typical scaffold protein and plays a role in cellular trafficking of other proteins (33). It has been wellestablished that the trafficking proteins of different sublocalization may have different functions in the cells (34, 35). In this study, we found NHERF1 A190D mutation resulted in an increase in the nuclear level of NHERF1, in a clear contrast to the WT NHERF1 protein. It has been shown that the PDZ1 domain of the NHERF1 protein is important in the importing the NHERF1 protein into the nucleus (29). The reported mutation in the present study is located at the PDZ2 domain of NHERF1. Our findings also show the PDZ2 domain of NHERF1 has an influence in importing this to the nucleus.

YAP (also known as YAP1 or YAP65) can interact with NHERF1 (8). YAP was first identified by its ability to associate with the SH3 domain of YES and SRC protein tyrosine kinases. When YAP is located in the nucleus, it acts as a transcriptional co-activator in cellular proliferation and other cancer-related malignant pathway (36). In this study, we found NHERF1 A190D mutation also appears to affect YAP function. The phosphorylation of YAP at serine 127 residue promotes its binding to 14-3-3 and impairs the nuclear import of YAP (37-39). NHERF1 A190D mutation led to a decrease in YAP phosphorylation. An increased binding affinity between mutated NHERF1 and YAP would lead to less phosphorylation of YAP, as shown in the present study. Therefore, the association between 14-3-3 protein and the phosphorylated serine residue of YAP would also decrease, facilitating YAP translocation into the nucleus and increasing its transcriptional activity. The novel influence of NHERF1 point mutation on cellular proliferation and migration suggests the regulation of PDZ scaffold protein would have great impact on cancer cells.

Here we found a novel NHERF1 A190D mutation which rescued cells from inhibited proliferation and migration by WT NHERF1, and affected localisation of NHERF1 and YAP proteins, both of which may have profound effects on cancer cell behaviour.

\section{Acknowledgements}

This work was supported by National Natural Science Foundation of the People's Republic of China (No. 81572704; 81472409). We wish also to thank Cancer Research Wales, National Research Network of Life Science for Wales (NRN/Ser Cymru) and the Albert Hung Foundation for their support.

\section{References}

1 Morales FC, Takahashi Y, Kreimann EL and Georgescu MM: Ezrin-radixin-moesin (ERM)-binding phosphoprotein 50 organizes ERM proteins at the apical membrane of polarized epithelia. Proc Natl Acad Sci USA 101: 17705-17710, 2004.

2 Lazar CS, Cresson CM, Lauffenburger DA and Gill GN: The $\mathrm{Na}^{+} / \mathrm{H}^{+}$exchanger regulatory factor stabilizes epidermal growth factor receptors at the cell surface. Mol Biol Cell 15: 5470-5480, 2004.

3 Hildreth KL, Wu JH, Barak LS, Exum ST, Kim LK, Peppel K and Freedman NJ: Phosphorylation of the platelet-derived growth factor receptor-beta by $G$ protein-coupled receptor kinase-2 reduces receptor signaling and interaction with the $\mathrm{Na}(+) / \mathrm{H}(+)$ exchanger regulatory factor. J Biol Chem 279: 41775-41782, 2004.

4 Takahashi Y, Morales FC, Kreimann EL and Georgescu MM: PTEN tumor suppressor associates with NHERF proteins to attenuate PDGF receptor signaling. EMBO J 25: 910-920, 2006.

5 Hall RA, Ostedgaard LS, Premont RT, Blitzer JT, Rahman N, Welsh MJ and Lefkowitz, RJ: A C-terminal motif found in the beta2-adrenergic receptor, P2Y1 receptor and cystic fibrosis transmembrane conductance regulator determines binding to the $\mathrm{Na}^{+} / \mathrm{H}^{+}$exchanger regulatory factor family of PDZ proteins. Proc Natl Acad Sci USA 95: 8496-8501, 1998.

6 Hall RA, Premont RT, Chow CW, Blitzer JT, Pitcher JA, Claing A, Stoffel RH, Barak LS, Shenolikar S, Weinman EJ, Grinstein S, Lefkowitz RJ: The beta2-adrenergic receptor interacts with the $\mathrm{Na}^{+} / \mathrm{H}^{+}$-exchanger regulatory factor to control $\mathrm{Na}^{+} / \mathrm{H}^{+}$ exchange. Nature 392: 626-630, 1998.

7 Dai JL, Wang L, Sahin AA, Broemeling LD, Schutte M and Pan Y: NHERF $\left(\mathrm{Na}^{+} / \mathrm{H}^{+}\right.$exchanger regulatory factor $)$gene mutations in human breast cancer. Oncogene 23: 8681-8687, 2004.

8 Mohler PJ, Kreda SM, Boucher RC, Sudol M, Stutts MJ and Milgram SL: Yes-associated protein 65 localizes p62(c-Yes) to the apical compartment of airway epithelia by association with EBP50. J Cell Biol 147: 879-890, 1999.

9 Weinman EJ, Wang Y, Wang F, Greer C, Steplock D and Shenolikar S: A C-terminal PDZ motif in NHE3 binds NHERF1 and enhances cAMP inhibition of sodium-hydrogen exchange. Biochemistry 42: 12662-12668, 2003. 
10 Salyer S, Lesousky N, Weinman EJ, Clark BJ, Lederer ED and Khundmiri SJ: Dopamine regulation of $\mathrm{Na}^{+}-\mathrm{K}^{+}$-ATPase requires the PDZ-2 domain of sodium hydrogen regulatory factor-1 (NHERF-1) in opossum kidney cells. Am J Physiol Cell Physiol 300: C425-434, 2011.

11 Jiang Y, Wang S, Holcomb J, Trescott L, Guan X, Hou Y, Brunzelle J, Sirinupong N, Li C, Yang Z: Crystallographic analysis of NHERF1-PLCbeta3 interaction provides structural basis for CXCR2 signaling in pancreatic cancer. Biochem Biophys Res Commun 446: 638-643, 2014.

12 Peng XL, Ji MY, Yang ZR, Song J and Dong WG: Tumor suppressor function of ezrin-radixin-moesin-binding phosphoprotein-50 through $\beta$-catenin/E-cadherin pathway in human hepatocellular cancer. World J Gastroenterol 19: 1306-1313, 2013.

13 Theisen CS, Wahl JK, Johnson KR and Wheelock MJ: NHERF Links the N-Cadherin/Catenin Complex to the Platelet-derived Growth Factor Receptor to Modulate the Actin Cytoskeleton and Regulate Cell Motility. Mol Biol Cell 18: 1220-1232, 2007.

14 Loureiro CA, Matos AM, Dias-Alves A, Pereira JF, Uliyakina I, Barros P, Amaral MD and Matos P: A molecular switch in the scaffold NHERF1 enables misfolded CFTR to evade the peripheral quality control checkpoint. Sci Signal 8: ra48, 2015.

15 Courbebaisse M, Leroy C, Bakouh N, Salaün C, Beck L, Grandchamp B, Planelles G, Hall RA, Friedlander G, Prié D: A new human NHERF1 mutation decreases renal phosphate transporter NPT2a expression by a PTH-independent mechanism. PLoS One 7: e34764, 2012.

16 Tornesello ML, Buonaguro L and Buonaguro FM: Mutations of the TP53 gene in adenocarcinoma and squamous cell carcinoma of the cervix: a systematic review. Gynecol Oncol 128: 442-448, 2012 .

17 Shapira I, Lee A, Vora R and Budman DR: P53 mutations in triple negative breast cancer upregulate endosomal recycling of epidermal growth factor receptor (EGFR) increasing its oncogenic potency. Crit Rev Oncol Hematol 88: 284-292, 2013.

18 Smith IN and Briggs JM: Structural mutation analysis of PTEN and its genotype-phenotype correlations in endometriosis and cancer. Proteins 84: 1625-1643 2016.

19 Mehrgou A and Akouchekian M: The importance of BRCA1 and BRCA2 genes mutations in breast cancer development. Med J Islam Repub Iran 30: 369, 2016.

20 Mangia A, Malfettone A, Saponaro C, Tommasi S, Simone G and Paradiso A: Human epidermal growth factor receptor 2, $\mathrm{Na}^{+} / \mathrm{H}^{+}$exchanger regulatory factor 1 , and breast cancer susceptibility gene-1 as new biomarkers for familial breast cancers. Hum Pathol 42: 1589-1595, 2011.

21 Pan Y, Wang L and Dai JL: Suppression of breast cancer cell growth by $\mathrm{Na}^{+} / \mathrm{H}^{+}$exchanger regulatory factor 1 (NHERF1). Breast Cancer Res 8: R63, 2006.

22 Pan Y, Weinman EJ and Dai JL: $\mathrm{Na}^{+} / \mathrm{H}^{+}$exchanger regulatory factor 1 inhibits platelet-derived growth factor signaling in breast cancer cells. Breast Cancer Res 10: R5, 2008.

23 Du G, Hao C, Gu Y, Wang Z, Jiang WG, He J and Cheng S: A Novel NHERF1 Mutation in Human Breast Cancer Inactivates Inhibition by NHERF1 Protein in EGFR Signaling. Anticancer Res 36: 1165-1173, 2016.

24 Bhattacharya S, Dai Z, Li J, Baxter S, Callaway DJ, Cowburn $\mathrm{D}$ and $\mathrm{Bu} \mathrm{Z}$ : A conformational switch in the scaffolding protein NHERF1 controls autoinhibition and complex formation. J Biol Chem 285: 9981-9994, 2011.
25 Cheng S, Li Y, Yang Y, Feng D, Yang L, Ma Q, Zheng S, Meng R, Wang S, Wang S, Jiang WG, He J: Breast cancer-derived K172N, D301V mutations abolish $\mathrm{Na}+\mathrm{H}+$ exchanger regulatory factor 1 inhibition of platelet-derived growth factor receptor signaling. FEBS Lett 587: 3289-3295, 2013.

26 Karim Z, Gérard B, Bakouh N, Alili R, Leroy C, Beck L, Silve C, Planelles G, Urena-Torres P, Grandchamp B, Friedlander G, Prié D: NHERF1 mutations and responsiveness of renal parathyroid hormone. N Engl J Med 359: 1128-1135, 2008

27 Guo CY, Xu XF, Wu JY and Liu SF: PCR-SSCP-DNA sequencing method in detecting PTEN gene mutation and its significance in human gastric cancer. World J Gastroenterol 14 : 3804-3811, 2008.

28 Cheng S, Zhang JQ, Zhu P, Ma YM, Xiong Y, Sun LC, Xu JG, Zhang $\mathrm{H}$ and He JQ: The PDZ domain protein CAL interacts with mGluR5a and modulates receptor expression. J Neurochem 112: 588-598, 2010

29 Du GF, Gu YN, Hao CC, Yuan Z, He JQ, Jiang WG and Cheng $\mathrm{S}$ : The cellular distribution of $\mathrm{Na}^{+} / \mathrm{H}^{+}$exchanger regulatory factor 1 is determined by the PDZ-I domain and regulates the malignant progression of breast cancer. Oncotarget 7: 29440-29453, 2016

30 Song J, Bai J, Yang W, Gabrielson EW, Chan DW and Zhang Z: Expression and clinicopathological significance of oestrogenresponsive ezrin -radixin -moesin -binding phosphoprotein 50 in breast cancer. Histopathology 51: 40-53, 2007.

31 Saponaro C, Malfettone A, Dell'Endice TS, Brunetti AE, Achimas-Cadariu P, Paradiso A and Mangia A: The prognostic value of the $\mathrm{Na}(+) / \mathrm{H}(+)$ exchanger regulatory factor 1 (NHERF1) protein in cancer. Cancer Biomark 14: 177-184, 2014.

32 Paradiso A, Scarpi E, Malfettone A, Addati T, Giotta F, Simone G, Amadori D and Mangia A: Nuclear NHERF1 expression as a prognostic marker in breast cancer. Cell Death Dis 4: e904, 2013.

33 Shenolikar S, Voltz JW, Minkoff CM, Wade JB and Weinman EJ: Targeted disruption of the mouse NHERF-1 gene promotes internalization of proximal tubule sodium-phosphate cotransporter type IIa and renal phosphate wasting. Proc Natl Acad Sci USA 99: 11470-11475, 2002.

34 Hoque MT and Cole SP: Down-regulation of $\mathrm{Na}^{+} / \mathrm{H}^{+}$exchanger regulatory factor 1 increases expression and function of multidrug resistance protein 4. Cancer Res 68: 4802-4809, 2008.

35 Karvar S, Suda J, Zhu L and Rockey DC: Distribution dynamics and functional importance of NHERF1 in regulation of Mrp-2 trafficking in hepatocytes. Am J Physiol Cell Physiol 307: C727737, 2014.

36 Zanconato F, Cordenonsi $\mathrm{M}$ and Piccolo S: YAP/TAZ at the Roots of Cancer. Cancer Cell 29: 783-803, 2016

37 Chan SW, Lim CJ, Chen L, Chong YF, Huang C, Song H and Hong W: The Hippo pathway in biological control and cancer development. J Cell Physiol 226: 928-939, 2010.

38 Luo X: Snapshots of a hybrid transcription factor in the Hippo pathway. Protein Cell 1: 811-819, 2011

39 Wang K, Degerny C, Xu M and Yang XJ: YAP, TAZ, and Yorkie: a conserved family of signal-responsive transcriptional coregulators in animal development and human disease. Biochem Cell Biol 87: 77-91, 2009.

Received November 9, 2016

Revised November 25, 2016

Accepted November 29, 2016 